\title{
COBRA: DE AQUEL OSCURO OBJETO DEL DESEO
}

\author{
POR \\ ENRIQUE MARQUEZ \\ Universidad de Miami
}

Sobre el soporte teórico-crítico de la narrativa de Severo Sarduy se ha mencionado la importancia del pensamiento de Jacques Derrida y, kangencialmente, el de Jacques Lacan ${ }^{1}$. Nos interesa, en el texto de Sarduy, Cobra (Buenos Aires, 1974)2 ${ }^{2}$, cuestionar la pertinencia del psicoanálisis lacaniano dentro de lo heterogéneo de su relato y los rasgos de éste que afectan tal punto de vista.

Según ha señalado Sarduy, su narrativa desea consignarse comola práctica de una "especie de psicoanálisis del lenguaje", partiendo de la premisa de que "el inconsciente español se estructura como un lenguaje barroco, con su exceso, sus extravagancias, la oposición oro/excremento y el flujo continuo (esto se puede ver en las oraciones de Cobra, por ejemplo), que ninguna "máquina", para seguir al Anti-Edipo de Guatari y Deleuze, puede cortar"s. Barroco muy español ciertamente, pero que comparte una visión lacaniana sobre la situación del sujeto, su inversión y sus erotismos.

La topología de Lacan, cimentada sobre los trabajos teóricos de Freud, trata de probar la condición del sujeto a partir de una carencia. Es esta carencia, esta ausencia o desposesión, lo que articula el deseo como un sistema metonímico de significaciones simbólicas a través de sus significantes (memory-traces en la terminología freudiana), y sus relaciones regidas por el azar inconsciente (inversión, condensación, supresión, transferencias, figurabilidad, etc.). En un plano narrativo, Sarduy trata de yuxtaponer varios niveles de significación para provocar lo que él llama una "lectura radial" en la cual todos los significantes aluden a otro que ha sido elidido, borrado, suprimido (como el nudo autónimo que señala Freud en los sueños), pero que apoyay domina, como el objeto perdido de Lacan, y del cual se derivan todas las manifestaciones del lenguaje, visto

\footnotetext{
1 Ver Roberto González-Echeverría, "The lost origin", Review 72 (Fall): 19-26.

2 Todas las citas provienen de esta edición.

${ }^{3}$ Entrevista hecha a Sarduy por Jean-Michel Fosey, "From Boom to Bing-Bang", Review 74 (Winter): 10-11.
} 
como sujeto. Uno de los niveles de significación de Cobra refiere a las infinitas combinaciones polisémicas que pueden obtenerse con el string formado por el grafema C-O-B-R-A platónico del hermafrodita original. Cobra es también Tiresias, quien agredió a dos serpientes que copulaban y fue convertido dos veces en su opuesto. Golpear a la serpiente (también cobra) significa en el mito conjurar las fuerzas generativas donde coexisten todas las parejas de opuestos: lo masculino y lo femenino, el ying y el yang, el nacimiento y la muerte, el placer y el dolor. Cobra es un Tiresias pop con "medio bigote y un seno", "sabe sobre la vida y la muerte", y no es más "que una concreción del primigenio cloruro viscoso, un engendro de la truculencia llena"6. Texto del deseo, texto del Otro, Cobra se articula de circularidades semánticas y fonológicas, parodias, trans-collages, espejeos borgianos y elaboraciones trans-textuales: el lenguaje como híbrido, objeto de una fantasmática desencadenada que provoca el desplazamiento de lo similar hacia lo heterogéneo; juego, disfraz, trasvestismo, carnaval, parodia, artificio barroco, todo se impulsa hacia la perversidad del juego del infante en la cual la progresión del placer cuenta más que la finalidad a la que conduce.

El cuerpo como signo pasional de donde parten, llegan y se transforman los impulsos eróticos, juega un papel decisivo en la articulación del texto. Es él quien impone la dialéctica erótica: posesión/desposesión, deseo/gasto vital, presencia/ausencia. Sus signos eróticos desarman y transfiguran la significación en una (a)-significación donde todo decir es un gesto de deseo, toda referencia es una vicisitud del cuerpo inmerso en lo heterogéneo y una coreografía del gesto lingüístico barbarizado por esa otra faz del lenguaje que es vaciamiento y placer.

Es este vaciamiento lo que está narrativizado en el texto y, para servirnos de la terminología de Propp, emplazado frente a un obstáculo: la posesión o desposesión del falo. Esta oposición aparece en el primero de los dos registros en que se divide el texto como una de las fuerzas generadoras de las mutaciones.

\footnotetext{
4 "It is not only because the material of the unconscious is a linguistic material ... that the unconscious is structured as a language. The question that the unconscious raises for you is a problem that touches the most sensitive point of the nature of langu age, that is the question of the subject. (....) Where is the subject? It is necessary to find the subject as a lost object. More precisely this lost object is the support of the subject". Jacques Lacan, "The Structure as an Inmixing", en The Structuralist Controversy, ed. por R. Macksey y E. Donato (Baltimore: John Hopkins University Press, 1970) 186. Referimos a este ensayo ya que en él Lacan condensa una extensa elaboración teórica explicitada en sus Ecrils (Paris: Seuil, 1966) y en Les qualre concepls fondamentaux de la psychanalyse (Le Seminaire, Livre XI) (Paris: Seuil, 1973).

3 Roberto González-Echevarria, "Rehearsal for Cobra", Review 74 (Winter): 15.

6 "Serpent: phallus-vagina, contraction of penis and mouth, indicating simultancously erection and swallowing, setting of the femenine orifice upon the male member, a totem of sexual origin". Phillipe Sollers, "La Boca Obra" Review 74 (Winter): 41.
} 
Cobra, por un lado, encarna la inversión del sujeto como trasvestí que encubre una identidad deteriorada tras un falso pronombre ("ella") y que "vela" su identidad asumida (femenina). Por otro lado, Eustaquio, el pintor-decoradorboxeador y dueño de un descomunal órgano sexual, sufre una serie de transformaciones de identidad y causa la desorganización de las coristas disfrazadas quienes le envidian su posesión fálica:

Era tal la cumbiamba que reinaba en los vericuetos del Templete que la Señora ya no sabía cómo intimidar a las meninas para que no perdieran el self-control según aparećáa Eustaquio el Sabrosón (p. 21).

El propio Eustaquio, en el segundo registro, se transforma en un curtidor de Marrakech que

le enseño (a Cobra), en el apartado de un cafetucho, el miembro, y así la sedujo y arrastró hasta el cementerio merinida: junto a un marabuto, sonriente, le sacó el precipitado erecto y también el puñal curvo con el mango incrustado, exigiéndole sin más rodeos la bolsa, y rogándole en nombre del profeta que abandonara de inmediato la empecinada búsqueda (p. 95).

En la sección de la iniciación de Cobra, tras su transformación quirúrgica, el falo asume categoría de totem religioso. El falo, significante del deseo erótico según Lacan, y de la plenitud, se convierte en una suerte de eucaristía:

De un cuerno de buey bebe y se vierte sobre el sexo un hidromiel opaco y acidulado. Bocabajo se frota el frenillo tenso - cuerda de masenko-, el glande bulboso y morado contra una piel de gamo que la leche mancha. (....) Baila y se embadurna de escarlata. Le fosforece enroscada en el sexo, una serpiente. Al glande se adhiere, blanda, la cabeza. Afilada, goteando leche, penetra la lengüeta (p. 142).

‥

Lentamente acariciado por ungüentos, cubierto de flores frescas, en el centro brilla el falo de basalto: una línea cifrada marca el frenillo. En el plato pulido que le sirve de base queda la leche espesa con que el oficiante lo baña (p. 240).

El Dr. Ktazob también ilustra la posesión fálica como una marca que define a un significante, en este caso, un personaje. Al principio, con su identidad encubierta por un disfraz de corista (la Cadillac), le hace la competencia a Cobra para convertirse en estrella del espectáculo de trasvestíes. Tras hacerse (a si misma) la operación quirúrgica, aparece como un negociante habanero hablando la jerga de los proxenetas. Más tarde, el disfraz le devuelve sus atributos femeninos.

De modo similar, la castración ejerce un campo de influencia en las mutaciones de los personajes. De forma inversa a cómo lo proclama la mitología burgesa capitalista, la castración asume en el texto dos funciones. Una es la de 
llegar a lo Otro, a lo inefable que queda siempre más allá del deseo; en vez de una modalidad de la prohibición, se invierte en una via posible para consumar la verdadera, la incesante transgresión erótica. Sin la posesión fálica la identidad deja de ser un estadio asignado por la cultura para dejar libre el paso a la primacía del deseo y la gratificación sexual más allá de todo límite. En tal circunstancia, sólo el movimiento erótico poseería realidad: la realidad y el deseo, lo prohibido y lo deseado, lo esperado y lo vivido, el cuerpo y su fantasma, serían todo uno. También en la castración la oposición muerte-deseo se armoniza, se junta y se elimina.

El texto ilustra la trayectoria hacia esa desvirtuación de los opuestos aniquilando el sujeto. Mientras Cobra, aún tras el disfraz, posee el significante erótico "falo", presenciamos su escisión como sujeto, creando una suerte de doble, Pup, la enana lunar, con atributos grotescos que se comporta como un niño. A ella se refiere Sarduy como Pup VCobra. La operación quirúrgica se lleva a cabo mediante una transferencia "sin anestesia", para que sufra la tortura de la castración; es en ella donde muere Pup, el doble infantil de Cobra. La transferencia ocurre a través de un complejo diagrama tras el cual se detecta el proceso de "necesidad-demanda de amor-deseo" meditado por Lacan, y en el cual todo proceso erótico significante alude a un Otro que es parte del sujeto.

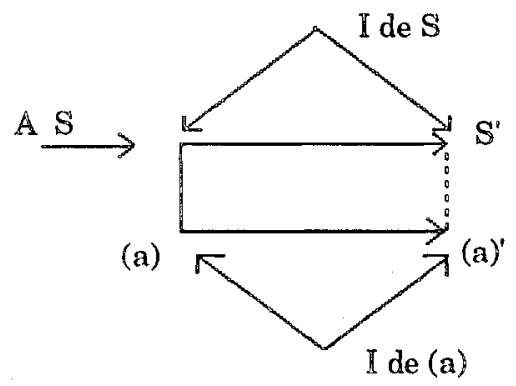

En el segundo registro, castrada y sin doble plasmado, Cobra se siente lista y capaz de buscar lo otro heterogéneo, lo prohibido, la otra orilla donde todo lo que deviene objeto de la fantasmática erótica (sado-masoquismo, pederastia, exaltación de las heces, canibalismo, etc) es experimentado como evento sacral. El suje to como conciencia, erradicado ya, abre las puertas para la libertad del ser en el deseo; la renuncia al sujeto, el sujeto que se auto-emascula, cede su lugar entonces a la búsqueda, búsqueda que en sí misma es ya posesión de un objeto parcial como objeto perdido.

La repulsa del sujeto hace que la castración, como obstáculo antepuesto a la posesión absoluta del Eros (Eros: ligar, unir), se transforme en una fastuosa ceremonia de placer y horror, equivalente acaso a la sensación de elevación que experimentan los santos. En ese sentido paradójicamente religioso (religar se 
invierte en des-ligar), los opuestos dolor/placer, muerte/Eros se anulan en éxtasis sexual, iluminación:

un santo alejandrino a quien, en sus origenes, tanto mortificaban los flujos luciferinos urticantes de su pudendo que, en un rapto extático y como poseído por serafines quirúrgicos, amputóse de un tajo el basilisco, entregándolo como piltrafa a los perros; así aligerado, ascendió, en un torbellino de sentencias gnósticas, al cimborio supremo del panteón platónico (p. 89).

La castración de Cobra se describe en terminos análogos:

Con una pinza de langosta Cadillac - San Ktazob tocaba a Cobra. Desnuda, alabastrina, microcéfala altísima, en espirales lentas la pinchada ascendía. Una almendra de llamas la escudaba; entre nubes concéntricas sus piececillos, sobre campos de estrellas, como ella centelleantes, sus ojos hú medos; un manto azul prusia, jirones de mar y cielo, iba a cubrirla; creando en el agua un remolino que chu paba remeros y colenates delfines, $a$ su alrededor giraba unes tromba de ángeles. En la quietud del vórtice, juntas en oración, sus manos. (p. 112 , el subrayado es nuestro).

Eliminado el sujeto como escisión, la búsqueda del objeto perdido se enuncia, según Lacan, como una empresa frustrada, un fracaso anticipado gracias al cual se articula la cadena erótica, el deseo liberado. Es este objeto (seno materno, heces, voz, cosa) lo que va a resultarle siempre ajeno al hombre, esquivo a su comprensión, marcando una alteridad, una fuga de la imagen de lo que se quiere poseer: el objeto (a) como un residuo inalcanzable de lo poseído, desajuste entre la realidad y su imagen fantasmática que engendra al sujeto. Lacan lo ilustra (S...S'...S"...Sn) donde la $S$ equivale al objeto erótico deseado (buscado) como significante y su interminable mutación en otra cosa, y la $x$ a la pérdida y encuentro simul táneos del sujeto en esa cacería del objeto paradisiaco totalmente inaccesible, irrepresentable e imposible ${ }^{7}$.

Tal objeto que siempre constata el fracaso del sujeto posesor se busca en Cobra en todos los niveles del erotismo: el sadismo, el masoquismo, el fetichismo, la masturbación, la pederastia, y otros. Según el propio Sarduy, ese periplo de lo imaginario tiene a su cargo promover el elemento lúdico, el derroche infantil: el sitio del Otro (como objeto perdido, paraíso perdido) es el azaroso trabajo de la inocencia perversa, de la caridad lúdica.

لluego, pérdida, des perdicio y placer: es decir, erotismo en cuanto que actividad puramente lúdica, que parodia de la función de reproducción, transgresión de lo útil, del "diálogo natural" de los cuerpos".

\footnotetext{
7 "The question of desire is that the fading subject yearns to find itself again by means of some sort of encounter with this miraculous thing defined by the phantasm. In its endeavor it is sustained by that which I call the lost object (....) which is such a terrible thing for the imagination". J. Lacan, 194.

${ }^{8}$ Severo Sarduy, Barroco (Buenos Aires: 1974) 101.
} 
El falo es, en el segundo registro, el signo que encarna el objeto perdido, velado en su engaño; para los integrantes de la pandilla que va a Nepal a adorar mandalas y falos tántricos. Pero ya en ese punto, se trata de un significante que flota, escindido de todo sujeto que quiera realmente poseerlo, y se desplaza hacia lo inefable, la muerte. Durante las peripecias de Cobra con la pandilla el sadismo encarna el trabajo hacia el objeto perdido. El sujeto renuncia aquí a su calidad de tal para poseer el objeto por la repetición, en la tortura, como ascesis de su cumplimiento. El dolor/placer se torna en éxtasis místico. Como en el caso del castrado, el arrebato erótico-religioso es simultáneo a la pérdida del sujeto, Es el salto al otro lado.

Hay en el texto más de una alusión al Leng T"che, "la tortura china de los cien pedazos, "que consiste en ir trucidando lentamente partes del cuerpo que no son vitales para que el atormentado pueda participar sin riesgo de muerte en la ceremonia. Durante la castración de Cobra se menciona el placer/dolor que experimenta la enana doble de Cobra. Luego es Cobra, como mediación entre la pandilla y el objeto, quien sufre torturas semejantes a manos de los integrantes del grupo:

Sea un murciélago aliabierto: clavarlo en una tabla. Entretenerse haciéndolo fumar. Se ahoga. Chilla. Darle fuego. Sea un conejo. Sea un Hombrecillo que sonrie atado a un madero. (....) Uno a uno, sin sangre -en los tendones de las articulaciones breves tajos-, separarlo en pedazos, uno a uno hasta cien. Que un traficante, fumando en pipa, lo señale. Una foto. Que una mujer ría (p. 114). ...

Atado a un árbol.

Triángulos de ligaduras en el pecho.

Dos surcos sanguinolientos le hinchaban las rodillas y los puños, le cercenaban los tobillos. (....) Preparán la cámara.

Flash: ícono lacerado por los infieles//máscara fang,

blanca contra las placas blancas de un árbol//actor ceniciento que se pliega bajo el peso de sus ornamentos ... (p. 153)

El placer, el dolor y su reverso de representación, de imagen fantasmática que congela el movimiento del objeto perdido, subrayan el doble carácter de ganancia y pérdida que comportan la castración y la tortura.

Así, en lo heteróclito de Cobra, creemos advertir un hilo lacaniano: la incapacidad de mantener un sujeto escindido en la búsqueda del erotismo libre $y$, tras salvar este obstáculo, la imposibilidad de poseer en vivo la imagen completa del objeto en cuya fuga el sujeto se pierde y vuelve a alcanzar un soporte para su erotismo, configuran en el texto verdaderas secuencias narrativas que contribuyen a imbricar la figura oculta que hace de Cobra una construcción barroca. Por un lado, el rechazo del sujeto da lugar a desplazamientos e inversiones de personajes, y a los vuelcos que por ellos sufre el texto. Por el otro, la repetición obstinada de buscar un objeto perdido, inapresable, el 
regodeo en la empresa inútil, colocan el texto en la órbita del juego, la plenitud, la gratificación narcisista, la representación de la representación. Ambos modulan también su aspecto "perverso": coexisten como sigros de lo imposible el rapto místico, la emasculación, lo orgiástico; en su lénguaje, una gran metáfora de la muerte y una no menor metonimia, la del deseo como su propia transgresión. 
